\title{
Antibiotics prescription and guidelines adherence in elderly: impact of the comorbidities
}

\author{
Anthony Dylis ${ }^{1}$, Anne Sophie Boureau', Audrey Coutant ${ }^{1}$, Eric Batard ${ }^{2,3}$, François Javaudinn ${ }^{2,3}$, Gilles Berrut ${ }^{1}$, \\ Laure de Decker ${ }^{1,2}$ and Guillaume Chapelet ${ }^{1,2^{*}}$
}

\begin{abstract}
Background: Although the interest of antibiotics is well known, antibiotics prescription is associated with side effect, especially in patients with multiples comorbidities. One way to reduce the incidence of side effects is to respect antibiotics prescriptions guidelines. Our objective was to investigated the factors associated with guidelines adherence in elderly patients with multiples comorbidities.

Methods: From October 2015 to December 2016, antibiotics prescription and guidelines adherence were analyzed in two post-acute care and rehabilitation services of a 2600-bed, university-affiliated center.

Results: One hundred and twenty-eight patients were included, fifty-nine (46\%) patients had antibiotics prescription according to guidelines. In Multivariable logistic regression analysis, prescription of 2 antibiotics or more $(\mathrm{OR}=0.168,95 \% \mathrm{IC}=0.037-0.758, p<0.05)$, 85 years of age and more $(\mathrm{OR}=0.375,95 \% \mathrm{IC}=0.151-0.931, p<$ $0.05)$ and the Charlson comorbidity index score ( $O R=0.750,95 \% \mathrm{IC}=0.572-0.984, p<0.05)$ were negatively associated with antibiotics prescriptions according to guidelines.
\end{abstract}

Conclusions: High comorbidity in the elderly was negatively associated with the guidelines adherence of antibiotics prescriptions. These criteria should be considered to optimize antibiotics prescriptions in elderly patients.

Keywords: Aged, 80 and over, Antibacterial agent, Charlson score comorbidity, Inappropriate prescribing

\section{Introduction}

Antibiotics are among the most prescribed drugs in the world [1]. Since the 2000s, there has been an increase of more than $20 \%$ of antibiotics prescriptions in elderly patients [2]. Antibiotics have undeniable benefit effects, but have also side effects that could represent a serious threat to public health [3]. Good quality of antibiotics prescription, defined by an adapted use of an antibacterial agent during an infection (molecule, dose and duration) and by the adherence of prescription guidelines, is associated with less side-effect $[4,5]$. Previous studies found that between 25 and $75 \%$ of antibiotics

\footnotetext{
* Correspondence: guillaume.chapelet@chu-nantes.fr

${ }^{1}$ Clinical Gerontology Department, Centre Hospitalier Universitaire de Nantes, 1 place Alexis-Ricordeau, F-44000 Nantes, France

2Université de Nantes, EE MiHAR (Microbiotes, Hôtes, Antibiotiques et Résistance bacterienne), Institut de Recherche en Santé (IRS2), 22 Boulevard bénoni-Goullin, F-44200 Nantes, France

Full list of author information is available at the end of the article
}

prescriptions did not meet the guidelines [6, 7]. To our knowledge, no studies have examined the relationship between the number of comorbidities and the adherence of antibiotics prescriptions guidelines in elderly patients [8], and considering the others confounding factors associated with antibiotic prescription [9-13].

The morbidity burden is defined by Valderas et al. as the total burden of types of illness having an impact on an individual's physiological reserve [14]. The presence of a high burden of comorbidity increases early mortality in bacterial infection, the number of hospitalizations and has a high public health impact [15]. A recent study in primary care found that a high burden of comorbidities is associated with an increased in antibiotic initiation [16]. However, this study did not specially examine whether treatments were initiated for bacterial infection and whether they were prescribed according to guidelines.

(c) The Author(s). 2019 Open Access This article is distributed under the terms of the Creative Commons Attribution 4.0 International License (http://creativecommons.org/licenses/by/4.0/), which permits unrestricted use, distribution, and reproduction in any medium, provided you give appropriate credit to the original author(s) and the source, provide a link to the Creative Commons license, and indicate if changes were made. The Creative Commons Public Domain Dedication waiver (http://creativecommons.org/publicdomain/zero/1.0/) applies to the data made available in this article, unless otherwise stated. 
The objective of this study was to examine the relationship between a high comorbidity index score and the adherence to antibiotics prescriptions guidelines, in elderly patients.

\section{Methods}

\section{Study population}

This retrospective cohort study was conducted in 2017 in Nantes University Hospital, a 2600-bed, universityaffiliated center, in the Clinical Gerontology Department, Nantes, France. All patients hospitalized in the postacute care and rehabilitation centers during 1st October 2015 and 31 December 2016 were screened before inclusion. Patient who received antibiotics treatments (enteral and parenteral) were identified and their electronic medical record were reviewed by two independent investigators. If the necessary information were not available in the electronic medical records, the medical papers records were reviewed. For inclusion, antibiotics had to be prescribed for suspicion of bacterial infection.

Bacterial infection was characterized according to the Mac Geer criteria [17]. These criteria take into account clinical and paraclinical presentation. Infection was considered as certain if all clinical and paraclinical criteria were presents. Infection was considered as probable if only clinical criteria were presents. For example, certain or probable case of pulmonary infection was distinguished by the presence of radiological pneumonia. If no criterion was present, antibiotic prescription was considered as not justified. A patient was not included if antibiotic was initiated in another service, prescribed for prophylaxis, or by local application. Only the first antibiotic prescription was taken into consideration.

\section{Adherence with guidelines}

The main study end-point of this study was adherence with guidelines. According to previous studies [6, 9], antibiotics prescriptions were considered in adherence if all the following criteria met the guidelines: molecule, dose and duration. The Guidelines (Additional file 1: Table S1) provided by the French Infectious Disease Society were considered [18-21]. Patients with other source of infection were not included. Antibiotics prescriptions recommendations are similar than those proposed by international guidelines [22-24].

Finally, patients were divided into two groups considering groups according to the presence or absence of adherence to the recommendations.

\section{Charlson comorbidity index score and confounding factors}

The Charlson comorbidity index score was used for the evaluation of the burden of comorbidities [25]. According to previous studies, the following variable were collected because of their associations with guidelines adherence or inappropriate drugs prescription in elderly patients [9-13]: 85 years and older, gender, cognitive impairment, history of falls during the last month, obesity (Body Mass Index > 30), presence of an indwelling urinary catheter, peritonitis, joint or bone infection, macrolide prescription, carbapenem prescription, first generation cephalosporin prescription, prescription of 2 antibiotic or more, 10 or more drugs per day, Instrumental of Activities Daily Living score (IADL), Activities of Daily Living score (ADL); serum creatinine higher than $120 \mu \mathrm{mol} /$ $\mathrm{L}$, recent advice from an infectiologist.

\section{Statistical analysis}

The participant's baseline characteristics were summarized using mean and standard deviations or frequencies and percentages, as appropriate. Between-group comparisons were performed using an independent simple T-test or chi square test $\left(\mathrm{X}^{2}\right)$ as appropriate. Univariable and Multivariable logistic regressions were performed to examine association between antibiotic prescription according to the guidelines and others variables. Variables with a significant association in Univariable analysis and/ or with $p$-value $<0.2$ were entered into a logistic regressions model for Multivariable analysis. Relative risks were expressed as odds ratios (OR) and 95\% confidence intervals. All reported p-value $<0.05$ were considered as statistically significant. Analysis was performed using SPSS software version 15.0 (SPSS, Inc., Chicago, IL, USA).

\section{Ethical consideration}

The study was conducted in accordance with the ethical standards set forth in Helsinki declaration (1983). The local ethical committee approved the study protocol.

\section{Results}

\section{Patient characteristics}

A thousand files were reviewed before inclusion (Fig. 1). Among them, 824 patients did not have antibiotics prescription. Among the 176 remaining patients, 48 were excluded: 4 because no guidelines could be used to assess the primary outcomes, 44 because no clinical or paraclinical information were available. Finally, 128 patients were included. The characteristics of the population are shown in Table 1 and Additional file 1: Table S2: 93 (73\%) patients were women, median age were 87 years old, the mean Charlson's comorbidity was 2.48 .

\section{Antibiotics prescriptions characteristics}

Antibiotics were prescribed for the following infectious disease: 32 (25\%) for pneumonia, 37 (29\%) for cystitis, 11 (9\%) for upper urinary tract infection (women) and 


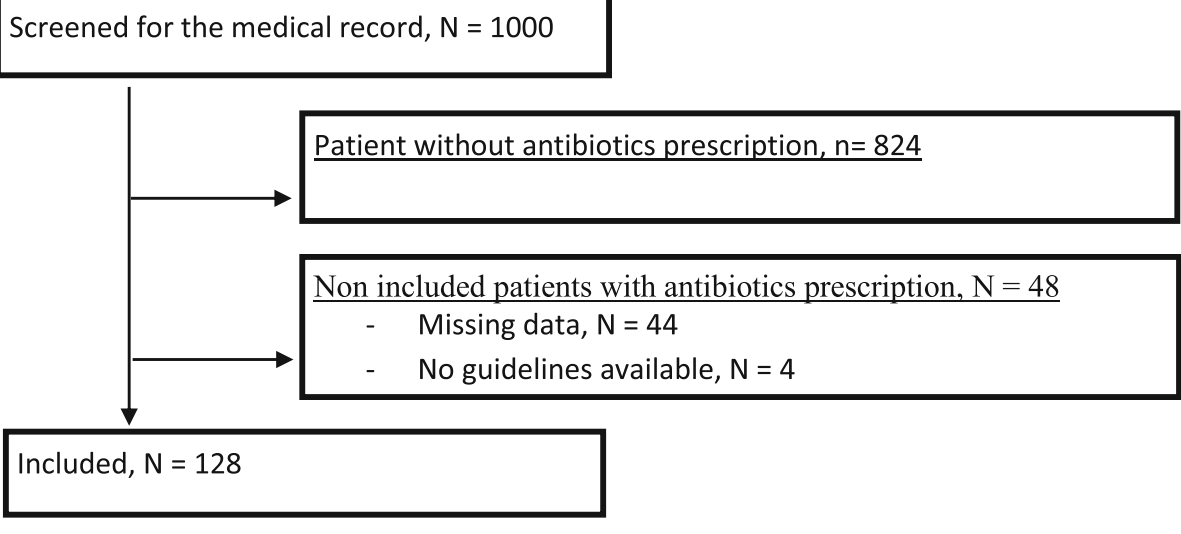

Fig. 1 Screening, exclusion and enrollment process of participants, $N=128$

11 (9\%) for male urinary tract infection (Additional file 1: Table S2). Among the 128 patients, guidelines were respected in $59(46 \%)$ patients, $32(25 \%)$ patients received antibiotics for uncertain diagnosis and 96 (75\%) received antibiotics for certain or probable bacterial infection. Among these 96 patients, 87 (90\%) patients had an adapted molecule (Additional file 1: Table S1), $62(71 \%)$ patients had an adapted molecule and an appropriate duration and 59 (61\%) patients had molecule, duration and dose adapted.

Table 1 Demographic and clinical characteristics of total population, $N=128$

\begin{tabular}{|c|c|c|c|c|}
\hline & $\begin{array}{l}\text { Total } \\
N=128(\%)\end{array}$ & $\begin{array}{l}\text { Antibiotics prescription in accordance } \\
\text { with the guidelines } N=59(\%)\end{array}$ & $\begin{array}{l}\text { Antibiotics prescription not in accordance } \\
\text { with the guidelines } N=69(\%)\end{array}$ & $p$-Value * \\
\hline Age. Years, mean +/-SD & $\begin{array}{l}87.05 \\
(5.402)\end{array}$ & $85.69(5.593)$ & $88.22(4.985)$ & 0.008 \\
\hline 85 years and more, $\mathrm{n}(\%)$ & $85(66.4)$ & $33(55.9)$ & $52(75.4)$ & 0.025 \\
\hline Women, n (\%) & $93(72.7)$ & $47(79.7)$ & $46(66.7)$ & 0.115 \\
\hline Length Of Stay (day) +/- SD & $\begin{array}{l}48.79 \\
(26.145)\end{array}$ & $51.32(25.741)$ & $46.31(26.523)$ & 0.307 \\
\hline Charlson score +/- SD & $2.48(2.280)$ & $2.17(2.127)$ & $2.75(2.385)$ & 0.149 \\
\hline $\mathrm{ADL}+/-\mathrm{SD}$ & $4.70(1.297)$ & $4.80(1.275)$ & $4.62(1.319)$ & 0.440 \\
\hline IADL +/- SD & $2.35(1.390)$ & $2.38(1.437)$ & $2.32(1.359)$ & 0.819 \\
\hline Serum albumin $(g / L)+/-S D$ & $\begin{array}{l}30.87 \\
(4.486)\end{array}$ & $31.11(4.897)$ & $30.66(4.111)$ & 0.576 \\
\hline Antibiotics treatment duration (day) $+/-$ SD & $7.80(3.067)$ & $7.70(1.832)$ & $7.88(3.851)$ & 0.754 \\
\hline$\geq 2$ antibiotics, n (\%) & $17(13.3)$ & $3(5.1)$ & $14(20.3)$ & 0.017 \\
\hline History of fall in the last month, n (\%) & $41(32)$ & $20(33.9)$ & $21(30.4)$ & 0.707 \\
\hline Chronic obstruction pulmonary disease, n (\%) & $6(4.7)$ & $2(3.4)$ & $4(5.8)$ & 0.686 \\
\hline Cognitive impairment, n (\%) & $29(22.7)$ & $16(27.1)$ & $13(18.8)$ & 0.295 \\
\hline Infectious advice, n (\%) & $2(1.6)$ & $1(1.7)$ & $1(1.4)$ & 1.000 \\
\hline Incontinence, n (\%) & $19(14.8)$ & $8(13.6)$ & $11(15.9)$ & 0.805 \\
\hline $\mathrm{BMI}>30 \mathrm{~kg} / \mathrm{m}^{2}, \mathrm{n}(\%)$ & $14(10.9)$ & $6(10.2)$ & $8(11.6)$ & 1.000 \\
\hline Presence of urinary catheter, n (\%) & $14(10.9)$ & $3(5.1)$ & $11(15.9)$ & 0.086 \\
\hline History of antibiotic allergy, n (\%) & $11(8.6)$ & $4(6.8)$ & $7(10.1)$ & 0.545 \\
\hline Presence of pressure ulcer, n (\%) & $9(7)$ & $6(10.2)$ & $3(4.3)$ & 0.300 \\
\hline Palliative care, n (\%) & $14(10.9)$ & $4(6.8)$ & $10(14.5)$ & 0.256 \\
\hline Over 10 treatments, n (\%) & $16(12.5)$ & $10(16.9)$ & $6(8.7)$ & 0.187 \\
\hline Serum creatinine $>120 \mu \mathrm{mol} / \mathrm{L}, \mathrm{n}(\%)$ & $18(14.1)$ & $7(11.9)$ & $11(15.9)$ & 0.612 \\
\hline
\end{tabular}


Table 2 Univariable and Multivariable logistic regression analysis of factors associated with antibiotic prescriptions according to the guidelines

\begin{tabular}{|c|c|c|c|c|}
\hline & \multicolumn{2}{|l|}{ Univariable Analysis } & \multicolumn{2}{|l|}{ Multivariable Analysis } \\
\hline & OR $(95 \% \mathrm{Cl})$ & $p$-Value & OR $(95 \% \mathrm{Cl})$ & $p$-Value \\
\hline 85 years and more & $0.415(0.196-0.879)$ & 0.022 & $0.375(0.151-0.931)$ & 0.035 \\
\hline Women & $1.958(0.873-4.392)$ & 0.103 & $0.897(0.311-2.585)$ & 0.840 \\
\hline Charlson score & $0.899(0.757-1.044)$ & 0.152 & $0.750(0.572-0.984)$ & 0.038 \\
\hline $\mathrm{ADL}$ & $1.118(0.844-1.482)$ & 0.436 & $1.008(0.659-1.543)$ & 0.969 \\
\hline IADL & $1.031(0.795-1.337)$ & 0.817 & $1.047(0.7-1.566)$ & 0.824 \\
\hline cognitive impairment & $1.603(0.697-3.686)$ & 0.267 & $1.217(0.442-3.354)$ & 0.704 \\
\hline Infectious advice & $1.17(0.07-19.16)$ & 0.911 & $0.852(0.044-16.629)$ & 0.916 \\
\hline $\mathrm{BMI}>30$ & $0.863(0.281-2.647)$ & 0.797 & $0.729(0.162-3.286)$ & 0.681 \\
\hline Presence of urinary catheter & $0.282(0.075-1.066)$ & 0.062 & $0.224(0.041 .245)$ & 0.087 \\
\hline Palliative care & $0.429(0.127-1.448)$ & 0.173 & $3.084(0.450-21.128)$ & 0.251 \\
\hline Over $>10$ therapy & $2.143(0.729-6.302)$ & 0.166 & $3.510(0.765-16.096)$ & 0.106 \\
\hline Serum creatinine $>120 \mu \mathrm{mol} / \mathrm{L}$ & $0.698(0.252-1.933)$ & 0.489 & $1.839(0.488-6.933)$ & 0.368 \\
\hline$\geq 2$ antibiotics & $0.210(0.057-0.773)$ & 0.19 & $0.168(0.037-0.758)$ & 0.02 \\
\hline
\end{tabular}

\section{Factors influencing antibiotic prescription according to the guidelines}

In Multivariable analysis (Table 2), the following factors were significantly associated with antibiotic prescription in accordance with guidelines: prescription of 2 antibiotics or more $(\mathrm{OR}=0.168,95 \% \mathrm{IC}=0.037-0.758, p<0.05) ; 85$ years of age and more $(\mathrm{OR}=0.375,95 \% \mathrm{IC}=0.151-0.931$, $p<0.05)$; Charlson comorbidity index score $(\mathrm{OR}=0.750$, $95 \%$ IC $=0.572-0.984, p<0.05)$.

\section{Discussion}

In this study, the following variables were negatively associated with antibiotic prescription according to the guidelines: Charlson's comorbidity index score, prescription of 2 antibiotics, patients aged 85 years and older.

The prevalence of antibiotics prescriptions in adhrence with guidelines (46\%) is consistent with other studies but is higher than another study carried out in a French nursing home $[6,26]$. Indeed, Boivin et al [6] have found a prevalence of $17 \%$. We make the assumption that this lower prevalence could be explained by three main arguments. First, quinolones prescriptions were considered as inappropriate by Boivin et al, and appropriate in this study, according to the guidelines $[18,19]$. Second, we did not consider if antibiotics prescriptions were reevaluated and switched at 48-72 $\mathrm{h}$ because of a high number of missing data. Third we assume that the MacGeer criteria could improve the accuracy of the diagnosis and could increase the number of appropriate prescriptions.

In this study, a high Charlson's comorbidity index score was a risk factor of antibiotics prescriptions not in adherence with guidelines. To our knowledge, this is the first description of this association. Previous studies have examined the association between antibiotics initiation and presence of comorbidities [27, 28], but without considering if the prescription was in adherence with guidelines. We assume that, together, two antibiotics bad practices could explain this result: inappropriate antibiotic initiation and absence of antibiotics prescription reevaluation. First, a physician could prescribe antibiotics earlier, and inappropriately in order to anticipate decompensation of comorbidities related to sepsis [28]. Second, Boivin et al. have found that a higher burden of comorbidities is associated with an absence of a systematic antibiotic prescription reevaluation [6]. Moreover, the study was conducted in a clinical ward where patients are treated by different senior doctors. Thus, prescribers were not always the one who reevaluated and stopped the prescription. We assume that this organization could also explain the difficulty to reevaluate and/or to stop the antibiotic.

In this study, 85 years of age and more has been negatively associated with antibiotic prescription in accordance with guidelines. To our knowledge, this is the first description of this association, that was previously described in another study that analyzed factors associated with inappropriate prescriptions in the elderly [11]. We assume that this result could be explained by two main arguments. First, age could have an impact on an earlier initiation of the antibiotics prescription. Indeed, Brooke et al. [29], in a study about factors influencing antibiotics prescription, proposed that physician may have fear of a rapid clinical aggravation in elderly patients, even in absence of clear evidence of bacterial infection. Second, as it was proposed for the Charlson comorbidity index score, the physician could have fear to stop antibiotics 
prescriptions in elderly patients even in absence of a high burden of comorbidities.

In this study, prescription of two antibiotics has been negatively associated with antibiotics prescription according to the guidelines. Kawanami et al. have already found this association in a recent study [13]. Our study confirms this result in a more specific population, vulnerable to side effects associated with antibiotics prescription [5]. This result can be explained by two arguments. First, physicians could initiate broad spectrum antibiotics prescriptions considering that the diagnosis of site of infection is not certain because of atypical clinical presentations [4]. Then, for the same reason, deprescribing to a narrower spectrum antibiotic may not be done [30]. In our study, no patient who initially received ceftriaxone or imidazole had further deprescription to a narrower-spectrum antibiotic. Second, we assume that a switch for another antibiotic can lead to inappropriate prescriptions. In this study, only three prescriptions were in accordance to the guideline when the antibiotic was switched for a narrower spectrum molecule, with a longer treatment duration.

Although it was previously described [9, 13], we did not find an association between guidelines adherence and the site of infection or the administration of a parenteral antimicrobial treatment. We assume that two methodological biases could explain these results. First our study may have been underpowered to detect these associations. Second, the population characteristics could be different. Indeed, Kawanami et al. included hospitalized patient, without age limit and described more gastro-intestinal infections, peritoneum infections or bone infections, associated with an inappropriate antibiotic prescription $[9,13]$. Moreover, in our study, no patient has been treated with cephalosporin 1st generation or aminoglycoside, which are antibiotics associated with inappropriate prescription $[9,13]$.

This study has limitations. First, this study had an observational design and we report the result of a retrospective analysis. Therefore, hidden bias could exist and may have underestimated the relationship between some factors and guidelines adherence. Second, because of the retrospective design, it was difficult to collect social or economic or morbimortality parameters that could be associated with guidelines adherence. Indeed, this study was not designed to analyze whether guidelines adherence is cost effective or reduced morbidity and mortality. Moreover, guidelines sometimes ignore vulnerable population such as frail elderly patients. Third, it is a French monocentric and study and the results may not be fully applicable to others settings with others guidelines. However, we assume that this population is representative of a population particularly vulnerable to infectious disease and with a higher risk of side-effects associated with antibiotics prescriptions [5]. Indeed, patients were predominantly female, with a median age of 87 years old, required assistance for activities of daily living, and the mean Charlson's index score was 2.48. Fourth, the Mac Geer criteria may not be fully adapted for the accuracy of the diagnosis of infection. We used the Mac Geer criteria because they take into account atypical semiological presentation in elderly patients [17], and we assume that they can be useful to asses antibiotics prescription in this population.

\section{Conclusion}

This study highlights the importance of co-morbidities in the prescription of antibiotics and more particularly on compliance with the guidelines. Further research is needed to identify other parameters involved in adherence with guidelines. Considering the impact on public health, these factors should be integrated into research protocols to improve and optimize antibiotic prescriptions.

\section{Additional file}

Additional file 1: Table S1. Site of infection and antibiotics recommended by the prescriptions guidelines. Table S2. Clinical characteristics of total population: site of infection and Antibiotics prescribed. (DOCX $28 \mathrm{~kb}$ )

\section{Acknowledgements \\ Not Applicable.}

\section{Authors' contributions}

ASB, GC, LdD: concept and design; ASB, GC, AC, LdD, AD: acquisition, analysis, and interpretation of data; FJ, EB, GB, LdD: drafting and revising the article critically for important intellectual content. All authors reviewed and approved the submitted version of the article.

\section{Funding}

No funding source.

\section{Availability of data and materials}

All data that were collected where listed in a encrypted and anonymous data base. The dataset is not available but can be requested from the corresponding author.

\section{Ethics approval and consent to participate}

This study was approved by the local ethics committee of Centre Hospitalier Universitaire of Nantes, the Groupe Nantais d'Ethique dans le Domaine de la Santé (GNEDS), study reference number RC17_0347. According to French regulation, no consent was required from patients in this retrospective study because the data were anonymized and encrypted.

\section{Consent for publication}

Not applicable.

\section{Competing interests}

The authors declare that they have no competing interests.

\section{Author details}

${ }^{1}$ Clinical Gerontology Department, Centre Hospitalier Universitaire de Nantes, 1 place Alexis-Ricordeau, F-44000 Nantes, France. ${ }^{2}$ Université de Nantes, EE MiHAR (Microbiotes, Hôtes, Antibiotiques et Résistance bacterienne), Institut de Recherche en Santé (IRS2), 22 Boulevard bénoni-Goullin, F-44200 Nantes, 
France. ${ }^{3}$ Emergency Department, Centre Hospitalier Universitaire de Nantes, 1 place Alexis-Ricordeau, F-44000 Nantes, France.

Received: 31 May 2019 Accepted: 29 August 2019

Published online: 29 October 2019

\section{References}

1. Van Boeckel TP, Gandra S, Ashok A, Caudron Q, Grenfell BT, Levin SA, et al. Global antibiotic consumption 2000 to 2010: an analysis of national pharmaceutical sales data. Lancet Infect Dis. 2014;14(8):742-50.

2. Bernier A, Delarocque-Astagneau E, Ligier C, Vibet M-A, Guillemot D, Watier L. Outpatient antibiotic use in France between 2000 and 2010: after the Nationwide campaign, it is time to focus on the elderly. Antimicrob Agents Chemother. 2014;58(1):71-7.

3. Laxminarayan R, Matsoso P, Pant S, Brower C, Røttingen J-A, Klugman K, et al. Access to effective antimicrobials: a worldwide challenge. Lancet. 2016; 387(10014):168-75.

4. Gavazzi G, Krause K-H. Ageing and infection. Lancet Infect Dis. 2002;2(11): 659-66.

5. Daneman N, Bronskill SE, Gruneir A, Newman AM, Fischer HD, Rochon PA, et al. Variability in antibiotic use across nursing homes and the risk of antibiotic-related adverse outcomes for individual residents. JAMA Intern Med. 2015;175(8):1331-9.

6. Boivin Y, Talon D, Leroy J, Floret N, Gbaguidi-Haore H, Bertrand X. Antibiotic prescription in nursing homes for dependent elderly people: a crosssectional study in Franche-Comté. Médecine Mal Infect. 2013:43(4):163-9.

7. Peron EP, Hirsch AA, Jury LA, Jump RLP, Donskey CJ. Another setting for stewardship: high rate of unnecessary antimicrobial use in a veterans affairs long-term care facility. J Am Geriatr Soc. 2013;61(2):289-90.

8. Francke AL, Smit MC, de Veer AJ, Mistiaen P. Factors influencing the implementation of clinical guidelines for health care professionals: a systematic meta-review. BMC Med Inform Decis Mak. 2008;8:38.

9. Ingram PR, Seet JM, Budgeon CA, Murray R. Point-prevalence study of inappropriate antibiotic use at a tertiary Australian hospital: brief communication. Intern Med J. 2012:42(6):719-21.

10. Fleming A, Bradley C, Cullinan S, Byrne S. Antibiotic prescribing in long-term care facilities: a meta-synthesis of qualitative research. Drugs Aging. 2015; 32(4):295-303.

11. Gallagher P, Lang PO, Cherubini A, Topinková E, Cruz-Jentoft A, Montero Errasquín B, et al. Prevalence of potentially inappropriate prescribing in an acutely ill population of older patients admitted to six European hospitals. Eur J Clin Pharmacol. 2011;67(11):1175-88.

12. Cool C, Cestac P, Laborde C, Lebaudy C, Rouch L, Lepage B, et al. Potentially inappropriate drug prescribing and associated factors in nursing homes. J Am Med Dir Assoc. 2014;15(11):850.e1-9.

13. Kawanami GH, Fortaleza CMCB. Factors predictive of inappropriateness in requests for parenteral antimicrobials for therapeutic purposes: a study in a small teaching hospital in Brazil. Scand J Infect Dis. 2011:43(6-7):528-35.

14. Valderas JM, Starfield B, Sibbald B, Salisbury C, Roland M. Defining comorbidity: implications for understanding health and health services. Ann Fam Med. 2009;7(4):357-63.

15. Cillóniz C, Polverino E, Ewig S, Aliberti S, Gabarrús A, Menéndez R, et al. Impact of age and comorbidity on cause and outcome in communityacquired pneumonia. Chest. 2013;144(3):999-1007.

16. Shallcross L, Beckley N, Rait G, Hayward A, Petersen I. Antibiotic prescribing frequency amongst patients in primary care: a cohort study using electronic health records. J Antimicrob Chemother. 2017;72(6):1818-24.

17. Stone ND, Ashraf MS, Calder J, Crnich CJ, Crossley K, Drinka PJ, et al. Surveillance definitions of infections in long-term care facilities: revisiting the McGeer criteria. Infect Control Hosp Epidemiol. 2012;33(10):965-77.

18. Caron F, Galperine T, Flateau C, Azria R, Bonacrosi S, Bruyère F, et al. Practice guidelines for the management of adult community-acquired tract infection. Med Mal Infect 2018:45(5):327-358.

19. Société de Pathologie Infectieuse de la Langue Française, Société de Pneumologie de la Langue Française, Agences Française de Sécurité Sanitaire des Produits de Santé. antibiothérapie par voie générale dans les infections respiratoires basses de l'adulte. France ; 2010. Available on: http:// www.infectiologie.com/site/medias/_documents/consensus/2010-infVRBspilf-afssaps.pdf. Accessed 21 Oct 2019.

20. Société de Pathologie Infectieuse de Langue Française et Societe française de dermatologie, Societe de pathologie infectieuse de langue française et société française de dermatologie. érysipele et fasciite nécrosante: prise en charge. France; 2000 p. 1-9. Available on: http:// www.infectiologie.com/site/medias/_documents/consensus/erysipelecourt-00.PDF. Accessed 21 Oct 2019.

21. Debast SB, Bauer MP, Kuijper EJ. European society of clinical microbiology and infectious diseases: update of the treatment guidance document for clostridium difficile infection. Clin Microbiol Infect. 2014;20:1-26.

22. Gupta K, Hooton TM, Naber KG, Wullt B, Colgan R, Miller LG, et al. International clinical practice guidelines for the treatment of acute uncomplicated cystitis and pyelonephritis in women: a 2010 update by the Infectious Diseases Society of America and the European Society for Microbiology and Infectious Diseases. Clin Infect Dis. 2011;52(5):e103-20

23. Mandell LA, Wunderink RG, Anzueto A, Bartlett JG, Campbell GD, Dean NC, et al. Infectious diseases society of America/American Thoracic Society consensus quidelines on the Management of Community-Acquired Pneumonia in adults. Clin Infect Dis. 2007;44(Supplement_2):S27-72.

24. Stevens DL, Bisno AL, Chambers HF, Dellinger EP, Goldstein EJC, Gorbach SL, et al. Practice guidelines for the diagnosis and Management of Skin and Soft Tissue Infections: 2014 update by the Infectious Diseases Society of America. Clin Infect Dis. 2014;59(2):e10-52.

25. Charlson M, Szatrowski TP, Peterson J, Gold J. Validation of a combined comorbidity index. J Clin Epidemiol. 1994:47(11):1245-51.

26. Nicolle LE, Bentley DW, Garibaldi R, Neuhaus EG, Smith PW. SHEA longterm-care committee. Antimicrobial use in long-term-care facilities. Infect Control Hosp Epidemiol. 2000;21(8):537-45 SHEA Long-Term-Care Committee.

27. Crnich CJ, Jump R, Trautner B, Sloane PD, Mody L. Optimizing antibiotic stewardship in nursing homes: a narrative review and recommendations for improvement. Drugs Aging. 2015;32(9):699-716.

28. van Buul LW, van der Steen JT, Doncker SM, Achterberg WP, Schellevis FG, Veenhuizen $\mathrm{RB}$, et al. Factors influencing antibiotic prescribing in long-term care facilities: a qualitative in-depth study. BMC Geriatr. 2014;14:1-11.

29. Brookes-Howell L, Hood K, Cooper L, Coenen S, Little P, Verheij T, et al. Clinical influences on antibiotic prescribing decisions for lower respiratory tract infection: a nine country qualitative study of variation in care. BMJ Open. 2012;2(3):1-7.

30. Leekha S, Terrell CL, Edson RS. General principles of antimicrobial therapy. Mayo Clin Proc. 2011;86(2):156-7.

\section{Publisher's Note}

Springer Nature remains neutral with regard to jurisdictional claims in published maps and institutional affiliations.

Ready to submit your research? Choose BMC and benefit from:

- fast, convenient online submission

- thorough peer review by experienced researchers in your field

- rapid publication on acceptance

- support for research data, including large and complex data types

- gold Open Access which fosters wider collaboration and increased citations

- maximum visibility for your research: over $100 \mathrm{M}$ website views per year

At $\mathrm{BMC}$, research is always in progress.

Learn more biomedcentral.com/submissions 